\title{
Impact Of Environmental Awareness On Consumer Attitudes- A Study Of Selected Green Products
}

\author{
Jubilee Goyal $^{1^{*}}$ ，Dr. H.S. Grewal ${ }^{2}$ \\ ${ }^{1}$ Assistant Professor, Graphic Era University, Dehradun \\ ${ }^{2}$ Dr. H.S. Grewal- Director and Professor, Management, Doon Business School, Dehradun
}

\begin{abstract}
This study aims to find the impact of environmental awareness on consumer attitudes for selected green products. The research was done on 600 respondents, both professionals and non-professionals in the city of Dehradun, capital of Uttarakhand, India. The objective was to study the respondent's level of environmental awareness, to measure their level of consumer attitudes and to observe the impact of environmental awareness on consumer attitudes. Also a comparison was made between the environmental awareness and consumer attitudes on two groups' professionals and non-professionals. The organic food products were the green products selected for this study. The total sample was equally divided into two group professionals and non-professionals. Stratified random sampling was used and all the subjects were matched on socio-economic status and age group.Environmental Awareness Test (EAWT) by Dr. K. Yeshodharawas used to assess the environmental awareness of the subjects. The Consumer Attitude Scale used was a 5 point Likert scale designed by the author. Mean, S.D. and ANOVAs' were used to infer findings and prove the proposed hypothesis. The findings revealed a significant difference in consumer attitudes of the respondents of the three levels of environmental awareness (high, medium and low)and also a significant difference in consumer attitudes of professionals and non-professionals.
\end{abstract}

Keywords:

Environmental awareness, Consumer attitudes, Organic food products, Dehradun, Professionals- Non-professionals

\section{INTRODUCTION}

One of the greatest challenges facing humanity is environmental degradation. Environmental degradation is the deterioration of the environment through depletion of resources such as air, water and soil. It is defined as any change or disturbance to the environmentperceived to be undesirable. Therefore, the awareness of environmental problems and the respond to these issues without delay is absolute necessary.Environmental issues in India include pollution, deforestation and various natural hazards, particularly cyclones and annual monsoon floods.

Public awareness on environmental issues is happening across the world. The environmental awareness plays an important and significant role in strengthening the sustainable development of any country, state or city. Environmental awareness stands for proper knowledge of environment and its problems towards which every individual should be aware of. Environmental awareness helps in the formation of consumer attitudes towards a product.

Several studies have been conducted on consumer attitudes with reference to organic food products throughout the world. These studies identified how consumers in different parts of the world perceive organic foods and form the basis of questionnaire designed to measure the consumer attitudes in this study.

Kollmuss and Agyeman (2002) define environmental awareness as "knowing the impact of human behaviour on the environment". It is a pre disposition to react to environmental issues in a certain manner (Culiberg and Rojšek, 2008).

It has also been found that the more the consumers are aware regarding the social and environmental issues, the more they are involved in pro-environmental behaviour (Panni, 2006). It includes the understanding of natural environment, a manner of treating the relation 
between human and nature; desire and action for environmental protection.

Consumer attitudes may be defined as an inner feeling of favourableness or unfavourableness towards a product or service offering and the 4Ps. As Blackwell, Miniard and Engel (2006)have defined, "Attitudes are an expression of inner feelings that reflect whether a person is favourably or unfavourably predisposed to some "object" and "Attitude formation, in turn, is the process by which individuals form feelings or opinions toward other people, products, ideas, activities, and other objects in their environment".

According to the relevant literature on organic food consumption, it appears that values concerned with health and environment influence consumer attitudes toward buying organic food (Chryssohoidis and Krystallis, 2005).

Most of the studies conducted in the past suggest that environmental awareness has an impact on consumer attitudes towards organic food products; however the degree of relationship varies in these studies.

\section{METHODOLOGY}

The mainobjective of the study was to find out the impact of three levels of awareness (high, medium , low) on consumer attitudes towards selected green products i.e. organic food products. Other objective includes a comparison between two variables environmental awareness and consumer attitudes on two groups' professionals and nonprofessionals.

\section{Sample:}

The study was done on 600 respondents equally divided into professionals and non-professionals in the city of Dehradun, capital of Uttarakhand, India. Stratified random sampling was used and all the subjects were matched on socio-economic status and age group.

\section{Design:}

The respondents were categorized into three levels of environmental awareness (high, medium and low).These levels were identified using quartile on Environmental Awareness Score, where scores below Q1 were considered low and above Q3 were considered high. Scores at Q2 were medium.

$3 * 2$ factorial design was used. Three levels of awareness and two levels of professionals and non-professionals yielding six conditions.

\section{Procedure:}

The respondents were given the Environmental Awareness Test (EAWT), to assess their level of environmental awareness. The respondents were then asked to complete the questionnaire followed by Consumer Attitude Scale (CAS). The scoring of EAWT was done on the basis of the instructions given in the manual. On the basis of the scores, the respondents were categorized on the basis of high, medium and low awareness. The scoring for CAS was done by the criteria laid down by the author. The collected data was analyzed .The proposed hypothesis were tested by the use of statistical tools Mean, S.D.'s and ANOVA's were computed. Based on the results obtained, interpretations were made.

\section{HYPOTHESIS}

H1- Respondents of all the three levels of Environmental Awareness (low, medium and high) will differ significantly from each other on consumer attitudes and its dimension.

H2- Respondents of Professionals and NonProfessionals will differ significantly from each other on consumer attitudes and its dimension.

\section{Tools:}

\section{Environmental Awareness Test (EAWT):}

Environmental Awareness Test (EAWT) was developed by $\mathrm{K}$. Yeshodhara in 2003. This test is intended to measure the level of environmental awareness of the respondents. The test consists of 36 multi- choice items, which focused on eight 
different areas of environmental awareness. The validity coefficient for the final test ranged from .60 to .76 which was significantly high.

\section{Consumer Attitude Scale (CAS):}

The questionnaire consists of aset of 45 items, to be answered by the respondents. A 5- point Likert scale has been used to measure the consumer attitudes towards the organic food products. Seven factors have been identified to assess the consumer attitudes. Factors that affect consumer attitudes are classified as: perception, factors favourable towards organic foods, factors against organic foods, price, ecological concern, company information and environmental knowledge.

\section{RESULTS AND INTERPRETATION}

To test the proposed hypothesis Mean, S.D.'s and ANOVA's were computed.

To test the first hypothesis, the obtained $\mathrm{F}$ value(Table 3) for all the three levels of environmental awareness (H,M, L) was found to be significant at .01level, showing that there is a significant difference between the three groups on consumer attitudes.

Mean values (Table 1) indicated that respondents with high level of environmental awareness obtained higher mean value followed by medium and low environmental awareness respondents. Respondents with high environmental awareness are found to be significantly higher on consumer attitudes followed by medium and low environmental awareness respondents.

On the various dimensions of consumer attitudes significant Fvalue for all the three levels of environmental awareness was found on perception, factors favourable towards the use of organic food products, price, ecological concern and company efforts, whereas no significant difference was found on factors against the use of organic food products and environmental knowledge.
The perception level, factors against the use of organic food products and ecological concern was found to be significantly higher with the respondents with high environmental awareness. The level of perception and factors against was lowest with the respondents having medium environmental awareness whereas lowest ecological concern was found in respondents having low environmental awareness.

Factors favourable towards the use of organic food products, price sensitivity, knowledge of companies and their efforts to promote organic food products and respondents environment knowledge was found to be significantly higher with respondents having medium level of environmental awareness.

Lowest level of factors favourable, price, company efforts and environmental knowledge was found in respondents having low environmental awareness.

On the basis of above results the proposed hypothesis H1 is partially accepted as significant difference in all the three levels of environmental awareness showed its impact on perception, factors favourable, price, ecological concern and company efforts leaving factors against and environmental knowledge.

The findings of the study is consistent with findings of Nor AzilaMohd Noor et al.(2012), that higher level of environmental awareness leads to favourable consumer attitudes towards green products. Similar findings have been found in the studies of (Paul and Rana,2012); (Kumar P. and Ghodeswar, 2015); (Onel and Mukherjee, 2016) and (Nagaraju and Thejaswini, 2016).

The results of $\mathrm{F}$ value (Table 3) for second hypothesis revealed that total of both the groups professionals and non-professionals was significant at .01 level, showing that there is consumer attitudes. 
Mean values obtained in study (Table 2) showed that professionals scored higher mean values on total consumer attitudes as compared to nonprofessionals. It means that professional consumers are significantly high on consumer attitudes than non-professional consumers.

Significant $F$ value between professionals and non-professionals was found on the dimension factors favourable towards organic food products indicating that professionals and non-professionals are different on this dimension, where as $\mathrm{F}$ value was not significant for other dimensions of consumer attitudes showing that there was no difference between the two groups on level of perception, factors against, price, ecological concern, company efforts and environmental knowledge.

Professional consumers were significantly higher on the level of perception, factors favourable towards the use of organic products, price sensitivity, ecological concern and environmental knowledge as compared to non-professional consumers. However non-professionals were significantly higher than professionals on the dimension factors against of consumer attitudes. No difference was found in both the groups on the knowledge of companies and their efforts to promote organic food products.

The $\mathrm{F}$ value of interaction effect of environmental awareness levels and professionals and nonprofessionals was found to be significant at .01 level. It means that all the three levels of environmental awareness when combined with professionals and non-professionals effect significantly on total consumer attitudes.

Accordingly, professionalswith medium level of environmental awareness are found to be significantly higher on consumer attitudes followed by professionals with high and low level of environmental awareness.Similarly nonprofessionals with high level of environmental awareness are significantly higher on consumer attitudes followed by non-professionals with medium and low level of environmental awareness.

On the basis of above results the second hypothesis $\mathbf{H 2}$ is partially accepted with professionals being higher on perception, factors favourable, price, ecological concern and environmental knowledge than non-professionals except two dimensions factors against and company efforts.

Findings of the study are consistent with the findings of( Padel and Foster, 2005); (Yiridoe, , Bonti-Ankomah \& Martin, 2005); (Mohamada et al., 2014) and (Kumar P. and Ghodeswar, 2015) who said that professionals and non-professionals differ in their consumer attitudes .

\section{REFERENCES}

[1] Allport, G.W. (1935). Attitude. In Murchinson, Worcester and Massachusetts (Ed.). A Handbook of Social Psychology, 798-844: Clark University Press.

[2] Anja Kollmuss\& Julian Agyeman (2002),“ Mind the Gap: why do people act environmentally and what are the barriers to pro-environmental behaviour?", Environmental Education Research, Vol. 8, No. 3.

[3] Barbara Culiberg and IčaRojšek (2010),“ Identifying service quality dimensions as antecedents to customer satisfaction in retail banking", Economic and Business Review, Vol. 12 ,No. 3 :151-166.

[4] Blackwell, R.D., Miniard, P.W. and Engel, J.F. (2006). Consumer Behaviour (10th ed.). Thomson Learning

[5] Chan, Kara, (2000), "Market segmentation of green consumers in Hong Kong." Journal of International Consumer Marketing12.2: 7-24.

[6] Justin Paul and Jyoti Rana (2012), "Consumer behaviour and purchase intention for organic food", Journal of 
Consumer Marketing, Vol. 29 Issue: 6 : 412-422.

[7] Krystallis, A. and Chryssohoidis, G. (2005), 'Consumers' Willingness to pay for organic food: factors that affect it and variation per organic product type", British Food Journal, 107: 320-343.

[8] Nagaraju.B. ,Thejaswini H.D (2016),“ A study on consumer attitude towards ecofriendly FMCG products with reference to Hubli city in Karnataka", IOSR Journal of Business and Management,Volume 18, Issue 11: 58-63.

[9] Naz Onel, Avinandan Mukherjee, (2016) "Consumer knowledge in proenvironmental behavior: An exploration of its antecedents and consequences", World Journal of Science, Technology and Sustainable Development, Vol. 13 Issue: 4, pp.328-352,

[10] Nor AzilaMohd Noor, Azli Muhammad, AzilahKassim, CikZuriana Muhammad Jamil, Norsiah Mat, Norazwa Mat and Hayat ul Safrah Salleh (2012), "Creating green consumers: how environmental knowledge and environmental attitude lead to green purchase behaviour?", International Journal of Arts \& Sciences.

[11] Padel S. and Foster C. (2005), "Exploring the gap between attitudes and behaviour", British Food Journal, 107(8):606-625.

[12] Panni, M.F.A.K. (2006), "The effect of consumerism towards customer attitudinal behavior in food industry in Malaysia", Multimedia University.

[13] Prashant Kumar and Bhimrao M Ghodeswar (2015),"Factors affecting consumers' green product purchase decisions", Marketing Intelligence \& Planning, Vol. 33 Issue: 3: 330-347.
[14] Yiridoe, E.K., Bonti-Ankomah, S. \& Martin, R.C. (2005), "Comparison of consumers perceptions and preferences toward organic versus conventionally produced foods: A review and update of the literature", Renewable Agriculture and Food System, Vol.20 : 193-205

[15] Boca, Gratiela Dana, and Sinan Saraçli. "Environmental education and student's perception, for sustainability." Sustainability 11.6 (2019): 1553.

[16] AWASTHI, ROCHNA. "EFFECT OF GREEN MARKETING ON BUYING PREFERENCES OF YOUNGSTERS." International Journal of Sales \& Marketing Management (IJSMM) 6.4, Jun-Jul 2017; 1-6

[17] KHAN, MZA, and N. Zafar Azeemi. "Statistical Correlation Between Consumer Tendency and Health Insurance Performance in UAE." (2016). International Journal of Business and General Management (IJBGM) 6. 1, Dec - Jan 2017; 1-12

[18] SHARMA, DEEPENDRA, and HARINDER PAL. "INVESTIGATION ABOUT CONSUMER ATTITUDE AND ITS ANTECEDENT TOWARDS ENVIRONMENTAL SUSTAINABLE APPAREL: A CASE STUDY IN INDIAN CONTEXT." International Journal of Environment, Ecology, Family and Urban Studies (IJEEFUS) 9.2, Apr 2019, 113-122 
Table 1: Mean and S.D. of High, Medium and Low level of Environmental Awareness on Consumer Attitudes

\begin{tabular}{|c|c|c|c|c|c|c|}
\hline \multirow{2}{*}{ Dimension } & \multicolumn{2}{|c|}{ Low Awareness } & \multicolumn{2}{c|}{$\begin{array}{c}\text { Medium } \\
\text { Awareness }\end{array}$} & \multicolumn{2}{l|}{ High Awareness } \\
\cline { 2 - 7 } & Mean & SD & Mean & SD & Mean & SD \\
\hline Perception & 15.33 & 3.21 & 15.15 & 3.92 & 17.07 & 3.49 \\
\hline Factors Favourable & 14.08 & 3.50 & 16.92 & 3.91 & 16.40 & 2.94 \\
\hline Factors Against & 13.33 & 3.72 & 12.93 & 3.89 & 13.83 & 3.65 \\
\hline Price & 15.65 & 3.48 & 18.05 & 3.48 & 16.54 & 3.13 \\
\hline $\begin{array}{c}\text { Ecological Concern } \\
\text { Company Efforts }\end{array}$ & 13.81 & 3.22 & 17.15 & 3.75 & 17.59 & 3.09 \\
\hline $\begin{array}{c}\text { Environmental } \\
\text { Knowledge }\end{array}$ & 15.53 & 3.38 & 16.83 & 3.39 & 16.60 & 3.41 \\
\hline Total & $\mathbf{1 0 4 . 0 6}$ & $\mathbf{9 . 7 6}$ & $\mathbf{1 1 4 . 0 1}$ & $\mathbf{1 2 . 3 0}$ & $\mathbf{1 1 4 . 8 5}$ & $\mathbf{9 . 3 8}$ \\
\hline
\end{tabular}

Table 2: Mean and S.D.'s of Consumers of Professional and Non- Professional Group

\begin{tabular}{|c|c|c|c|c|}
\hline \multirow{2}{*}{ Dimension } & \multicolumn{2}{|c|}{ Professionals } & \multicolumn{2}{c|}{ Non- Professionals } \\
\cline { 2 - 5 } & Mean & S.D.'s & Mean & S.D.'s \\
\hline Perception & 16.11 & 3.80 & 15.59 & 3.92 \\
\hline Factors Favourable & 16.62 & 3.72 & 14.97 & 4.02 \\
\hline Factors Against & 13.26 & 3.76 & 13.47 & 3.91 \\
\hline Price & 16.77 & 3.42 & 16.73 & 3.93 \\
\hline Ecological Concern & 16.42 & 3.76 & 15.94 & 4.05 \\
\hline
\end{tabular}




\begin{tabular}{|c|c|c|c|c|}
\hline Company Efforts & 16.32 & 3.42 & 16.32 & 3.76 \\
\hline Environmental Knowledge & 16.86 & 3.17 & 16.54 & 3.54 \\
\hline Total & $\mathbf{1 1 2 . 3 7}$ & $\mathbf{1 1 . 0 6}$ & $\mathbf{1 0 9 . 5 7}$ & $\mathbf{1 3 . 9 4}$ \\
\hline
\end{tabular}

Table 3: Analysis of Variance

\begin{tabular}{|c|c|c|c|}
\hline Dimension & $\begin{array}{c}\text { F Value } \\
\text { H. M.L. } \\
\text { Awareness }\end{array}$ & $\begin{array}{c}\text { F Value } \\
\text { P. / Non P. }\end{array}$ & $\begin{array}{c}\text { Interaction F } \\
\text { H.M.L.: P./Non P. }\end{array}$ \\
\hline Perception & $17.50 * *$ & 3.18 N.S. & $1.01 \quad$ N.S. \\
\hline Factors Favourable & $37.03 * *$ & $32.93 * *$ & $9.06 * *$ \\
\hline Factors Against & 2.86 N.S. & 0.46 N.S. & 0.29 N.S. \\
\hline Price & $25.60 * *$ & $0.02 \quad$ N.S. & $19.02 * *$ \\
\hline Ecological Concern & $73.73 * *$ & 2.99 N.S. & 5.08 \\
\hline Company Efforts & $8.25 * *$ & 0.00 N.S. & $9.73 * *$ \\
\hline Environ. Knowledge & $2.21 \quad$ N.S. & $1.43 \quad$ N.S. & $0.01 \quad$ N.S. \\
\hline Total & $63.05 * *$ & $10.26 * *$ & $11.58 * *$ \\
\hline
\end{tabular}

